experience and his innovations and contributions to the field of neurosurgery, spinal injuries and to our journal are innumerable. He is a Fellow of the Royal Society of Edinburgh. He is also a member of many learned societies, Scottish, British and international. $\mathrm{He}$ is a founder member and chairman or past chairman of many learned societies, including the International Medical Society of Paraplegia and the Scottish Association of Neurological Sciences, a founder member and immediate past president of the British Cervical Spine Society, and Director of Spinal Injury Studies of the World Federation of Neurosurgical Societies.

$\mathrm{He}$ has been instrumental in the instigation and the development of many spinal injuries centres in different parts of the world. A visiting professor and guest lecturer to many institutions, he recently had the privilege to deliver the Donald Munro

\section{Message from the publisher}

This is a special issue of the journal in more than one way. It marks the thirtieth anniversary of Paraplegia's publication as a major medical title, it is also the tenth year of $\mathrm{Mr}$ Phillip Harris as editor, and of least importance to most readers but of great significance to me marks, literally, the birth day of Macmillan as the publisher of the journal.

As a new boy it is inappropriate for me to attempt to recall the events of the past 30 years since Professor Sir Ludwig Guttmann founded both the International Medical Society of Paraplegia and this journal others more competent than I will most certainly do so. I am sure however that most of the major innovations and attendant discussion on all aspects of spinal injury have appeared in the pages of this journal over the years and will continue so to do.
Lecture in the United States of America. $\mathrm{Mr}$ Phillip Harris has recently been elected president of the Rotary Club of Edinburgh, an honour bestowed on few.

Our editor is reaching his seventieth birthday and his tenth anniversary as the editor of our 30 year old journal. We commence this year with a new publisher and a much improved format, confident that our journal will continue to be the main reference for clinicians in the field, for authors in and related to the field and for future generations of clinicians.

We extend our best wishes to the readers of Paraplegia, and to the editorial board. To our editor we also express our special thanks from two loyal colleagues of the journal.

\section{W S El Masry MB B Ch FRCSE \\ Assistant Editor \\ J T Hughes MD FRCP FRCPath \\ Assistant Editor}

When a journal has been as successful as Paraplegia it becomes something of an institution in its own right. One learns not to trifle with an institution lightly! The changes you will see in this issue of Paraplegia, a revised cover and, we hope, more pleasing typography, are less significant than the change to a monthly publication schedule. This change in the frequency of publication should allow more material to be published expeditiously in future.

Macmillan are delighted to be associated with the Society in the publication of this the thirtieth anniversary issue and look forward with them to developing the journal in its next decade.

Harry Holt 